\title{
Perancangan Multimedia Interaktif Tentang Kesenian Jaranan Turangga Yaksa Sebagai Media Pembelajaran Di SDN 3 Pringapus Kabupaten Trenggalek
}

\author{
Nerin Sulistiani ${ }^{1}$, Faldi Hendrawan ${ }^{2}$, Abdulloh Eizzi Irsyada ${ }^{3}$ \\ ${ }^{1,2,3}$ Desain Komunikasi Visual, ${ }^{4}$ Informatika \\ 1nerintyan@gmail.com, ${ }^{2}$ faldikobenasia@gmail.com, ${ }^{3}$ abdulloheizzi@ asia.ac.id
}

\begin{abstract}
ABSTRAK
Pemahaman budaya daerah perlu dimiliki setiap orang sejak dini. Pada SDN 3 Pringapus mempelajari kesenian jaranan Turangga Yaksa untuk mengenalkan kepada siswanya. Akan tetapi proses belajar yang hanya terpaku pada buku serta kurangnya faktor interaktif, sehingga menurunnya minat belajar siswa. Dengan semakin berkembangnya teknologi informasi, upaya untuk meningkatkan minat belajar anak dapat dilakukan dengan berbagai media, salah satunya adalah menggunakan media interaktif. Oleh karena itu dirancang sebuah multimedia interaktif menggunakan software pengolah multimedia. Karakter yang digunakan adalah karakter anak lengkap dengan pakaian jaranan dengan muka yang ceria, warna yang dominan hijau, dan warna dasar serta teks yang sederhana supaya mudah dibaca untuk memahami materi yang disampaikan oleh siswa. Setelah proses selesai maka selanjutnya pengujian efektivitas produk dengan cara penyebaran kuisioner. Hasil yang didapat dalam penelitian melalui penyebaran kuisioner yang telah dilakukan di SDN III Pringapus kecamatan Dongko kabupaten Trenggalek, dapat ditarik kesimpulan bahwa 93\% media pembelajaran ini dikatakan efektif.
\end{abstract}

Kata Kunci: Media Pembelajaran, Kesenian Jaranan, Turangga Yaksa, Multimedia Interaktif.

\begin{abstract}
Understanding of regional culture needs to be owned by everyone from an early age. At SDN 3 Pringapus studied the art of jaranan Turangga Yaksa to introduce his students. But the learning process is only fixed on the book and the lack of interactive factors, so that students' interest in learning decreases. With the development of information technology, efforts to increase children's learning interest can be done with various media, one of which is using interactive media. Therefore designed an interactive multimedia using multimedia processing software.

The character used is the character of the child complete with jaranan clothes with a cheerful face, the dominant color is green, and the basic colors and text are simple so that it is easy to read to understand the material conveyed by students. After the process is complete, then testing the effectiveness of the product by distributing questionnaires.

The results obtained in the study through the distribution of questionnaires that have been conducted at SDN III Pringapus in Dongko sub-district, Trenggalek district, can be concluded that 93\% of the learning media are said to be effective.
\end{abstract}

Keywords: Learning Media, Art Jaranan, Turangga Yaksa, Interactive Multimedia.

\section{PENDAHULUAN}

Kabupaten Trenggalek merupakan salah satu dari kabupaten di Jawa Timur yang memiliki beberapa macam budaya salah satunya kesenian jaranan Turangga Yaksa. Pengetahuan tentang budaya daerah sangat penting agar budaya tersebut tetap dilestarikan selain itu dapat menambah pengetahuan dan wawasan kepada masyarakat. Budaya kesenian Jaranan Turangga Yaksa merupakan warisan secara turun temurun dari generasi ke generasi pada ruang lingkup daerah tersebut yang harus dikenalkan dan dipelajari sejak dini. Tahapan dasar pengenalan yaitu pada sekolah dasar. Pelajaran kesenian Jaranan Turangga Yaksa ini diterapkan di kelas ekstrakurikuler dan merupakan kelas wajib untuk siswa SDN 3 
Pringapus. Melalui ekstrakurikuler tersebut pembelajaran kesenian jaranan Turangga Yaksa dapat dikembangkan nilai-nilai sosial budaya bagi siswa sekolah dasar berupa rasa tanggung jawab, sikap toleransi, dan pentingnya melestarikan suatu keragaman budaya.

SDN 3 Pringapus adalah salah satu Sekolah Dasar yang berada di Desa Pringapus Kecamatan Dongko KabupatenTrenggalek. Fasilitas yang dimiliki lumayan lengkap dengan adanya komputer walaupun cuma beberapa dan LCD proyektor. Akan tetapi proses belajarmengajar pada SDN III Pringapus yang hanya terpaku pada buku serta kurangnya faktor media interaktif mengakibatkan murid akan merasa jenuh dan bosan, sehingga menurunnya minat belajar anak dalam mempelajari budaya daerah yaitu kesenian jaranan Turangga Yaksa. Selama ini materi pelajaran tentang kesenian jaranan untuk beberapa siswa dianggap membosankan, baik strategi maupun teknik pembelajarannya. Dengan adanya fasilitas komputer yang ada cukup disesalkan karena belum dimanfaatkannya dengan baik. Pada buku Nana Sudjana berpendapat "Guru yang terlalu sering menggunakan tanya jawab dan membahas menyimpang dari bahan pelajaran membuat siswa bosan dan akan mencapai titik jenuh dalam mengajukan pertanyaan dan menjawab pertanyaan guru" (Sudjana, 2013:3).

Pembelajaran berbasis multimedia interaktif dapat mempermudah siswa dalam belajar kesenian jaranan turangga yaksa. Selain itu pembelajaran dengan menggunakan multimedia interaktif akan membuat proses pembelajaran kesenian jaranan Turangga Yaksa lebih menarik dan interaktif. Penggunaan multimedia dalam pembelajaran juga akan membantu siswa mengenal teknologi sejak usia dini. Media pembelajaran adalah segala sesuatu yang digunakan untuk menyalurkan pesan, dan dapat merangsang pikiran, perasaan, perhatian, dan kemauan peserta didik sehingga dapat mendorong terjadinya proses belajar yang disengaja, bertujuan dan terkendali (Hasrul, 2011:3).

Berdasarkan uraian di atas maka diambil judul artikel "Perancangan Multimedia Interaktif Tentang Kesenian Jaranan Turangga Yaksa Sebagai Media Pembelajaran di SDN 3 Pringapus Kabupaten Trenggalek" dan diharapkan dengan adanya media pembelajaran yang berupa multimedia interaktif kesenian jaranan Turangga Yaksa ini dapat meningkatkan minat 3 belajar siswa serta mempermudah siswa dalam menerima materi menjadi lebih menyenangkan.

\section{PEMBAHASAN}

\section{Konsep Perancangan}

Dalam pembuatan aplikasi ini memadukan empat unsur penting yaitu teks untuk memberikan keterangan secara tertulis selain sebagai penjelasan suatu materi yang akan disampaikan, teks juga digunakan untuk memberikan keterangan gambar yang akan ditampilkan dalam aplikasi yang dibuat. Gambar disini untuk menambah tampilan agar lebih menarik dan gambar juga bisa digunakan sebagai penjelas dengan apa yang telah disampaikan. Suara untuk mengetahui tombol yang telah diklik dan juga sebagai iringan aplikasi agar tidak jenuh ketika menjalankan aplikasi. Video untuk memperjelas gerakan secara nyata. Dengan memadukan empat unsur tersebut, aplikasi akan menjadi lebih menarik serta tidak monoton, sehingga menimbulkan kenyamanan pada pemakai untuk menggunakan aplikasi. 
Desain yang baik mempunyai titik berat untuk menarik perhatian (Centre of Interest). Ada berbagai cara untuk menarik perhatian kepada titik berat tersebut, yaitu dapat dicapai melalui perulangan ukuran serta kontras antara tekstur, nada warna, garis, ruang, bentuk atau motif (Kartika, 2004:63). Multimedia interaktif ini merupakan aplikasi yang berkaitan dengan materi ekskul, belajar kesenian jaranan Turangga Yaksa untuk siswa sekolah dasar kelas IVI di SDN III Pringapus. Deskripsi produk terdiri dari jenis produk, tema, judul produk, frame output, target pasar, serta media distribusi yang akan di pakai. Yang dapat dilihat pada table 1 .

Tabel 1 Deskripsi produk

\begin{tabular}{ll}
\hline Jenis Produk & Multimedia pembelajaran interaktif (Incuiry) \\
\hline Tema & Kesenian jaranan \\
\hline Judul produk & Belajar jaranan Turangga Yaksa \\
\hline Frame output & Resolusi output $800 \times 600$ \\
\hline Target pasar & Siswa Sekolah Dasar kelas I-VI \\
\hline Media distribusi & Media offline
\end{tabular}

\section{Elemen Audio Visual}

Aplikasi yang dibuat akan diisi dengan beberapa elemen untuk memberikan kemudahan dalam penyampaian informasi tentang pembelajaran kesenian jaranan melalui multimedia pembelajaran interaktif, antara lain :

\section{Tombol}

Berikut beberapa tombol yang akan ditampilkan di media pembelajaran untuk mempermudah pengguna dalam mengoperasikan aplikasi, dapat dilihat pada table 2 .

Tabel 2. Tombol

\begin{tabular}{c} 
Icon \\
\hline 1
\end{tabular}




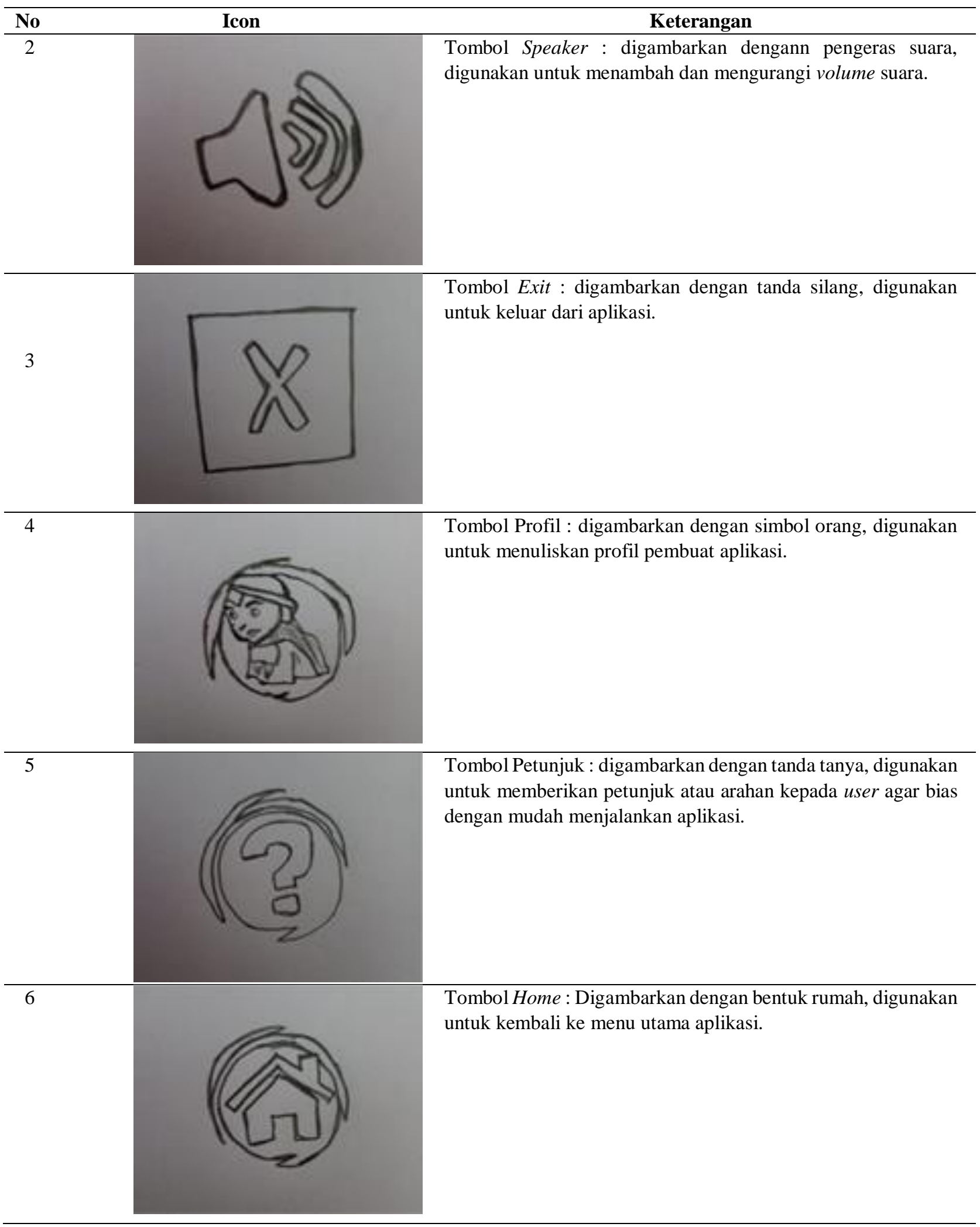




\begin{tabular}{|c|c|c|}
\hline No & Icon & Keterangan \\
\hline 7 & & $\begin{array}{l}\text { Tombol Sejarah : Digambarkan dengan buku, karena sejarah } \\
\text { identik dengan buku-buku yang ada di perpustakaan . }\end{array}$ \\
\hline 8 & & $\begin{array}{l}\text { Tombol Gerakan Tari : Digambarkan dengan orang yang } \\
\text { sedang menari diambil dari salah satu gerakan tari yang ada. }\end{array}$ \\
\hline 9 & & $\begin{array}{l}\text { Tombol Musik : Digambarkan dengan salah satu musik yang } \\
\text { dipakai dalam pertunjukan jaranan. }\end{array}$ \\
\hline 10 & & $\begin{array}{l}\text { Tombol Kostum : Digambarkan dengan salah satu } \\
\text { perlengkapan yang dipakai untuk pertunjukan jaranan. }\end{array}$ \\
\hline 11 & & $\begin{array}{l}\text { Tombol galeri : Digambarkan dengan orang berfoto, karena } \\
\text { pada galeri berisi kumpulan gambar-gambar. }\end{array}$ \\
\hline
\end{tabular}

\section{Karakter}

Karakter akan digunakan pada halaman pembuka/intro. Proses setelah pembuatan gambar karakter adalah scanning, yang dilanjutkan ke tahap pengeditan. Pada tahap ini yang digunakan adalah software corel draw. Karakter ini dibuat disesuaikan dengan karakter anak 
yang lucu, dengan raut wajah yang ceria serta pakaian yang lengkap untuk sebuah pertunjukan kesenian jaranan. Karakter dapat dilihat pada gambar 1.

\section{Layout}

Elemen-elemen desain yang telah dibuat akan disusun menjadi suatu kesatuan agar tidak membosankan. Penggunaan jenis layout akan digunakan dalam pembuatan media pembelajaran interaktif ini, sehingga gambar dan teks akan disusun secara teratur dan tetap memperhatikan prinsip-prinsip layout seperti picture windows layout, frame, dan silhouette.

\section{Audio}

Terdapat satu audio yang akan dipakai dalam multimedia pembelajaran interaktif ini. Audio tersebut berbentuk sebuah instrumen lagu yaitu musik jawa instrumental. Audio tersebut dipakai pada halaman pembuka, halaman menu, halaman profil, halaman sejarah, halaman gerak, halaman kostum, halaman galeri, halaman musik dan halaman petunjuk. Sedangkan audio untuk tombol menu pada aplikasi menggunakan audio yang sederhana.

\section{Proses Produksi}

Proses produksi ini merupakan tahap yang paling penting karena sangat berpengaruh untuk hasil perancangannya.

\section{Pra Produksi}

Peta navigasi ini adalah sebagai petunjuk arah dari perjalanan aplikasi dan merupakan struktur penting dalam pembuatan aplikasi multimedia pembelajaran interaktif, diagram alur/navigasi pada diagram berikut.

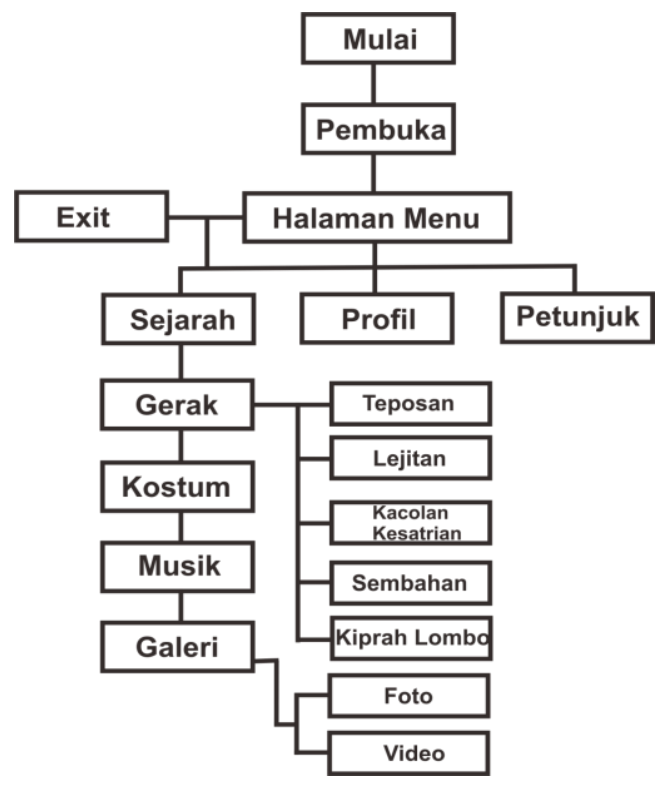

Gambar 1. Diagram Alur 


\section{Perancangan Storyboard}

Pada Pembuatan media pembelajaran ini untuk perancangan menggunakan storyboard.

Storyboard dapat dilihat pada table 3.

Tabel 3. Storyboard

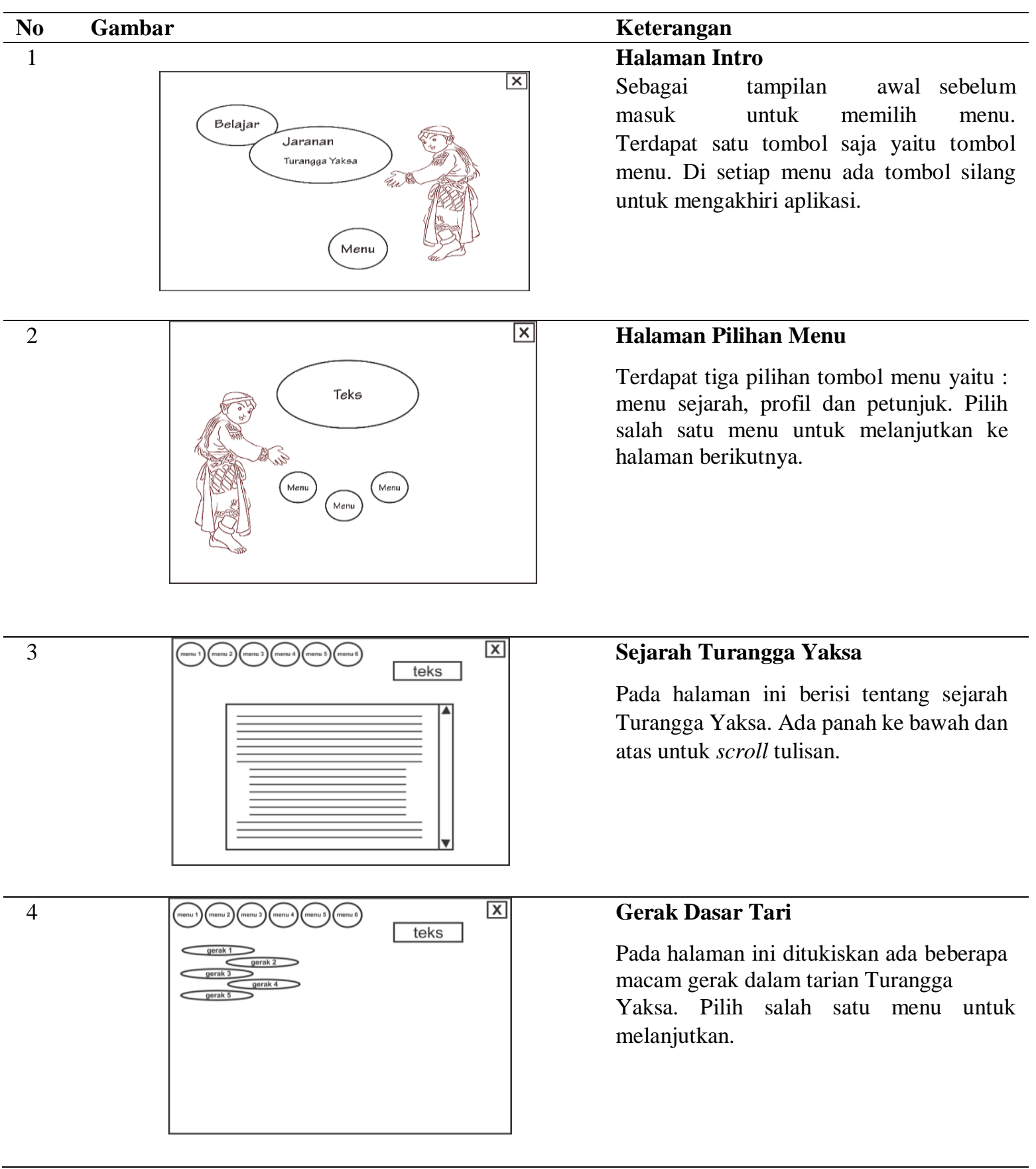




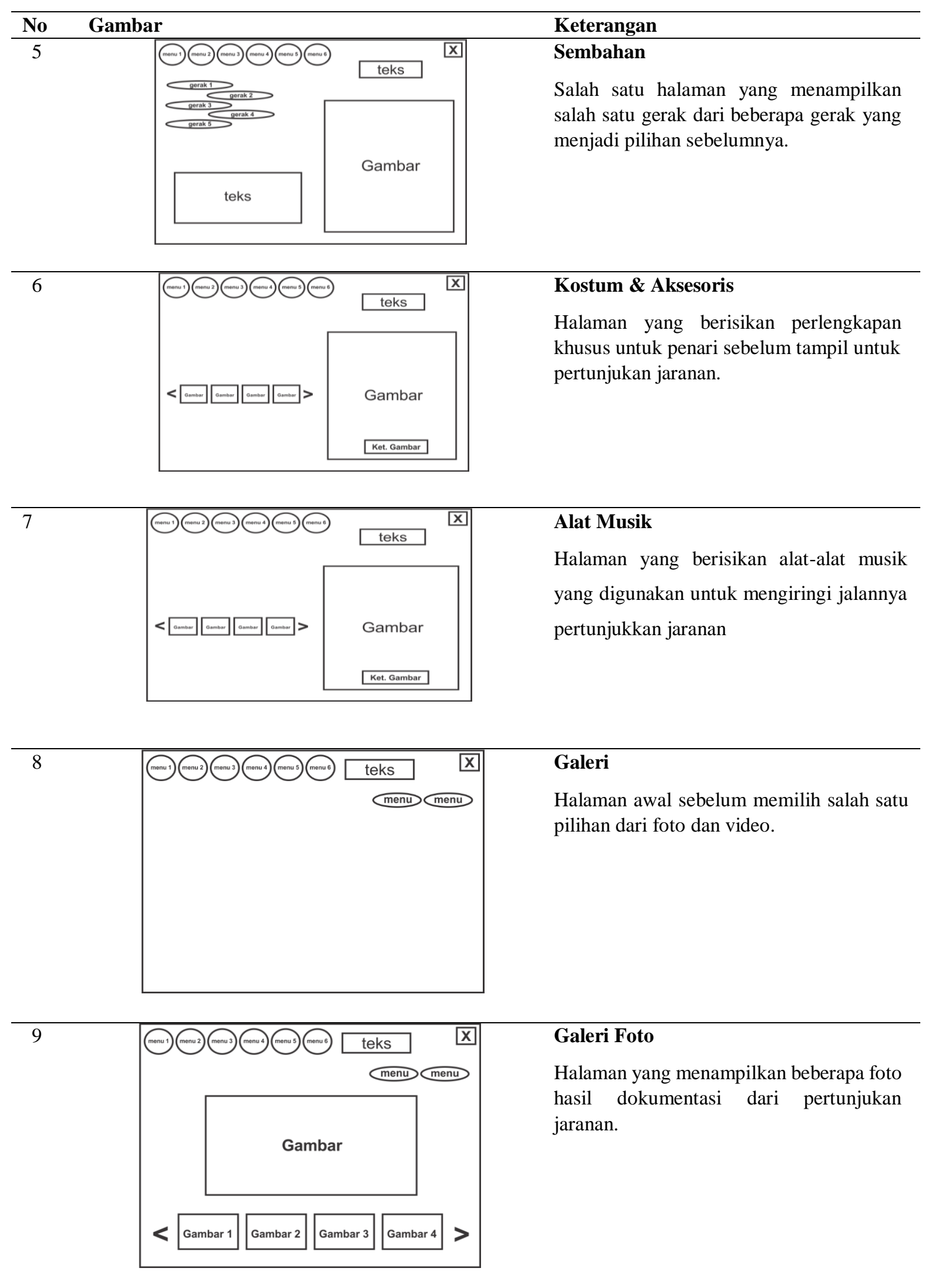




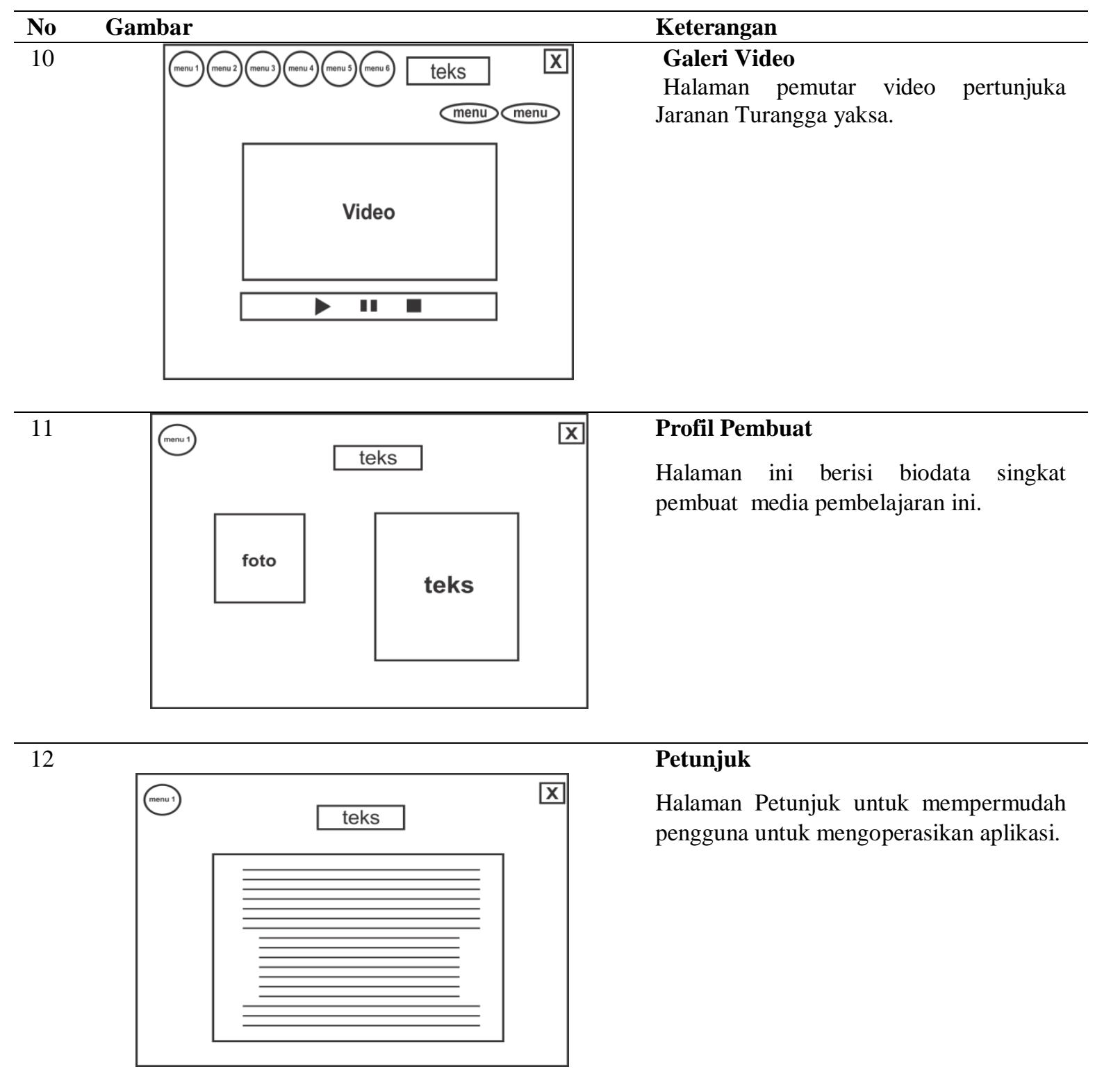

Setelah tersusun sebuah storyboard yang jelas, selanjutnya akan masuk proses inti yakni pembahasan tentang media pembelajaran secara menyeluruh atau implementasi program. Implementasi merupakan penerapan dari rancangan konsep atau ide yang sudah dibuat untuk dipraktekkan dalam proses pembuatan yang meliputi beberapa hal, diantaranya adalah produksi dan pasca produksi.

\section{Proses Produksi}

\section{Visualisasi}

Visualisasi adalah tahap dimana membuat perancangan objek disuatu aplikasi. Tahap visualisasi yaitu perancangan objek atau karakter, perancangan background, tombol, penganimasian dan publishing. Salah satu yang berpengaruh dalam visualisasi adalah 
tipografi. Tipografi berkaitan dengan penataan huruf melalui media manual berupa lempeng baja yang timbul atau karet (stempel) yang timbul berkenaan dengan tinta dan akan dituangkan kepermukaan kertas (Kusriyanto, 2007 : 38).

\section{Perancangan Objek}

Perancangan objek di mulai dari menggambar manual, setelah pembuatan gambar selesai lanjut ke proses scanning dan dilanjutkan ke proses tracing di CorelDraw X7. Perancangan karakter dapat dilihat pada gambar 2.

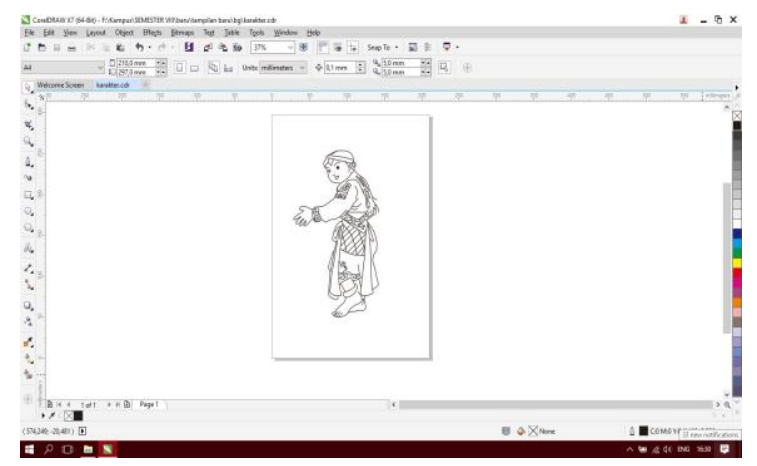

Gambar 2. Perancangan Karakter

Setelah selesai proses tracing di CorelDraw lalu memberi pewarnaan. Pewarnaan menggunakan Interacttive Fill Toll. Warna dapat didefinisikan secara objektif atau fisik sebagai sifat cahaya yang dipancarkan, secara subjektif atau psikologis sebagai bagian dari pengalaman indra penglihatan (Sanyoto, 2005 :9). Pewarnaan karakter dapat dilihat pada gambar 4.

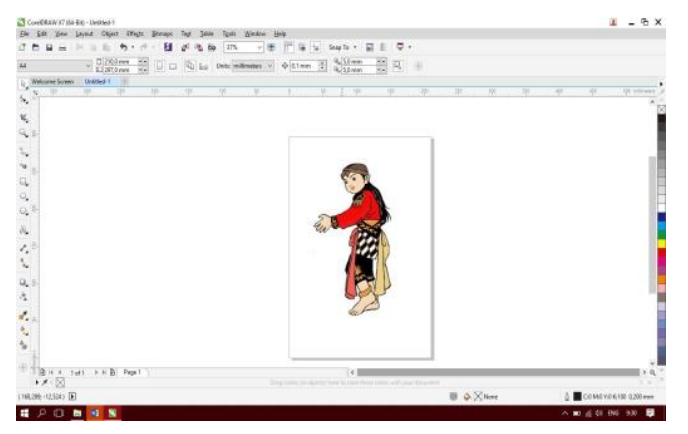

Gambar 3. Hasil Pewarnaan Karakter

\section{Perancangan Background}

Gambar ini akan digunakan sebagai background dibeberapa halaman menu media pembelajaran yang akan dibuat. Perancangan background dapat dilihat pada gambar 4 . 


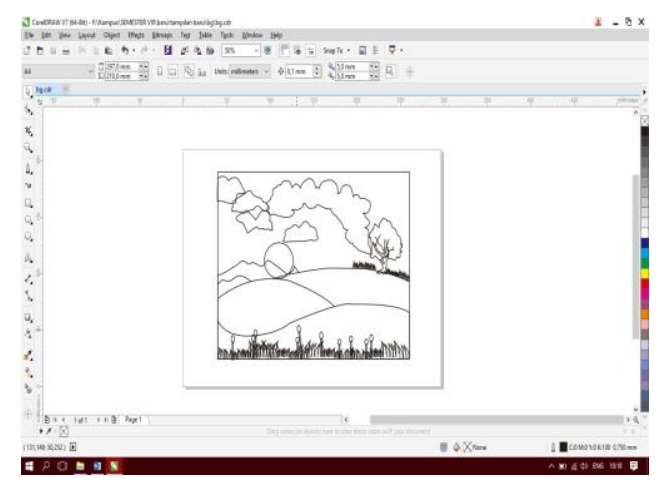

Gambar 4. Perancangan Background

Setelah selesai proses perancangan background, selanjutnya ke proses pewarnaan. Untuk pewarnaan menggunakan Interacttive Fill Toll.

\section{Perancangan Tombol}

Perancangan tombol digambar di CorelDraw menggunakan pen toll. Setelah gambar selesai lanjut ke pewarnaan, sedangkan untuk pemberian efek lebih tebal menggunakan Adobe Photoshop.

\section{Penganimasian}

Selanjutnya adalah proses penganimasian yang ditulis dalam bentuk script flash. Langkah pertama adalah membuka software Adobe Flash CS6 dan klik Create New pilih Action Script 2.0. Setelah membuka lembar kerja baru, selanjutnya mengubah ukuran lembar kerja Adobe Flash CS6 menjadi 800 x 600 pixels, lalu masukkan gambar ke lembar kerja flash. Convert gambar dapat dilihat pada gambar 5.

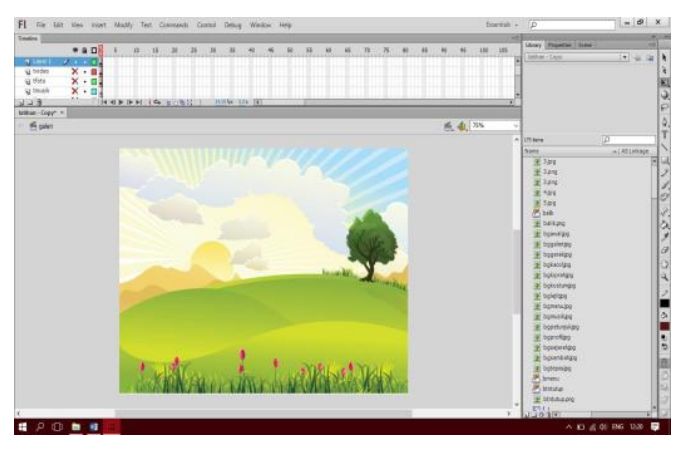

Gambar 5. Convert Gambar 


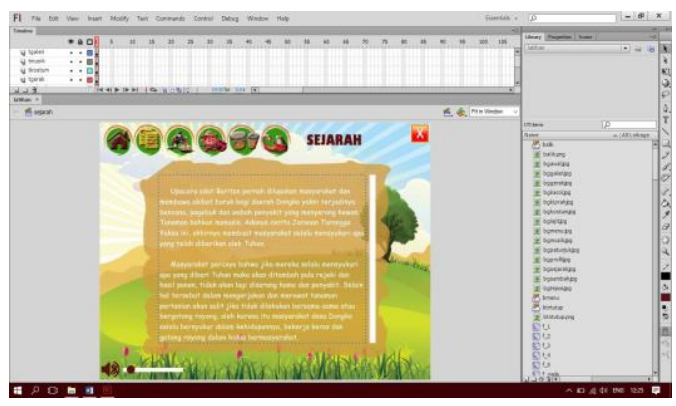

Gambar 6. Gambar di Library

Setelah gambar sudah masuk di library dan sudah tertata di lembar kerja selanjutnya memberikan script atau coding program di layer masing- masing tampilan. Berikut beberapa tampilan dan script yang terdapat di tombol masing-masing menu untuk melanjutkan ke tampilan yang diinginkan.

\section{Publishing}

Setelah semua sudah selesai maka selanjutnya akan mempublish aplikasi yang sudah dibuat ke dalam format exe. Klik menu File $\rightarrow$ Publish setting, selanjutnya berikan tanda cek pada windows projector (.exe) lalu klik tombol publish $\rightarrow$ ok. Publish Setting dapat dilihat pada gambar 7 .

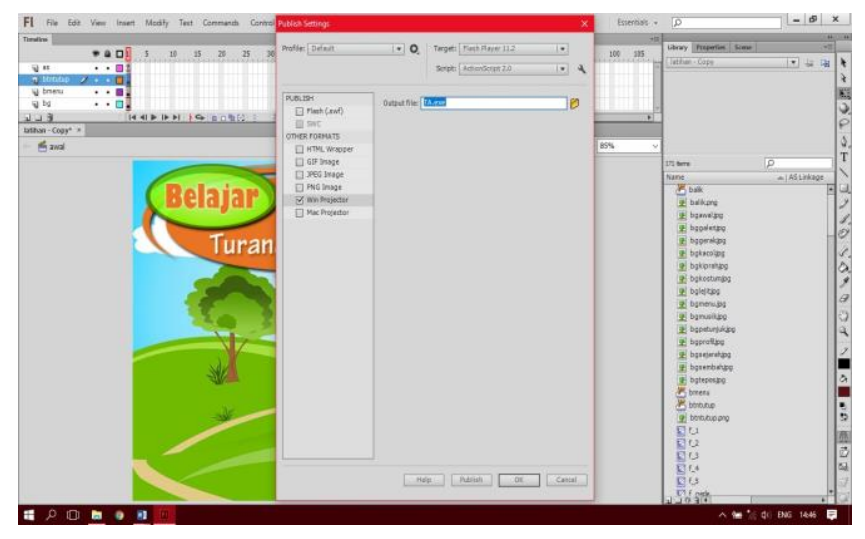

Gambar 7. Publish Setting

\section{Packaging}

Hasil akhir dari media pembelajaran ini adalah berupa aplikasi dengan format exe dan juga dikemas dalam bentuk DVD sebagai sarananya, dapat dilihat pada gambar 15 .

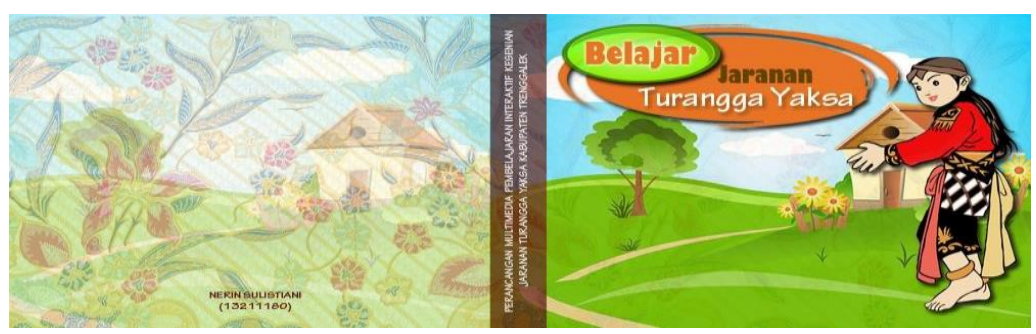




\section{Gambar 8. Cover Sampul DVD}

\section{Pengujian Efektivitas Produk}

Pengujian yang dilakukan secara tes kuisioner dengan jawaban

"Ya" dan "Tidak" untuk murid SDN III Pringapus, Trenggalek secara langsung untuk menilai hasil program aplikasi pembuatan media pembelajaran jaranan Turangga Yaksa. Total kuisioner yang dibagikan kepada murid SDN III Pringapus, Trenggalek berjumlah 30 lembar. Untuk mengetahui hasil akhir dari data yang diperoleh, maka untuk perhitungan rekapitulasi menggunakan rumus aritmatika yaitu sebagai berikut:

Hasil Kuisioner

Nilai Akhir $=$ X Jumlah Kuisioner

Persentase

Sehingga nantinya diperoleh penilaian akhir dalam bentuk prosentase sebagai berikut :

Jika $<50 \%$, maka aplikasi program tidak layak untuk dipublikasikan dan jika $>50 \%$ aplikasi layak untuk dipublikasikan.

Jawaban "Ya" artinya setuju dengan materi yang dibuat di aplikasi, sedangkan jawaban "Tidak" maka sebaliknya responden tidak setuju atau tidak tertarik dengan materi yang diberikan. Dari seluruh data yang sudah ada, jika dihitung menggunakan rumus matematika tersebut maka diperoleh hasil sebagai berikut :

Untuk presentase jawaban YA (setuju):

933

Nilai Akhir $=-$ X $10=93 \%$ $100 \%$

Untuk presentase jawaban TIDAK (tidak setuju):

67

Nilai Akhir $=\frac{}{100 \%} \times 10=7 \%$

Dari hasil kuisioner, responden lebih banyak memilih jawaban "Ya" daripada yang “Tidak". Maka dapat disimpulkan bahwa media pembelajaran jaranan Turangga Yaksa ini efektif untuk pembelajaran dan layak untuk dipublikasikan. 


\section{KESIMPULAN}

Kesimpulan dari perancangan multimedia interaktif tentang kesenian jaranan Turangga Yaksa ini adalah sebagai materi pembelajaran kesenian Jaranan Turangga Yaksa di kelas ekstrakurikuler pada SDN III Pringapus. Memiliki kegunaan untuk memudahkan anakanak dalam belajar secara mudah dan praktis melalui komputer dan mempunyai manfaat untuk mendapatkan pengetahuan dan pengalaman mengenai proses atau tahapan-tahapan bagaimana cara mudah mempelajari kesenian Jaranan Turangga Yaksa. Hasil pembelajaran yang ingin dicapai agar anak dapat mengekspresikan dirinya melalui pembelajaran interaktif kesenian Jaranan Turangga Yaksa secara bertahap dalam bidang kesenian jaranan. Proses perancangan media pembelajaran ini dimulai dari pembuatan storyboard, karakter, desain layout, edit gambar dengan menggunakan beberapa software pengolah gambar, dan sampai proses terakhir pengemasan dalam bentuk CD. Hasil dari penyebaran kuisioner pada SDN III Pringapus kelas I-VI dapat dikatakan efektif karena memperoleh nilai presentase 93\% dengan jawaban Ya, yang berarti setuju dengan media pembelajaran yang telah dibuat.

\section{DAFTAR PUSTAKA}

Hasrul. Desain Media Pembelajaran Animasi Berbasis Adobe Flash CS3 pada Mata Kuliah Instalasi Listrik 2. Jurnal Medtek. 2011

Kartika, Dharsono Sony. Pengantar Estetika. Bandung Rekayasa Sains. Cetakan Pertama. Penerbit ITB. 2004.

Kusriyanto, Adi. Pengantar Desain Komunikasi Visual. Yogyakarta. 2007.

Sudjana, Nana. Penelitian Hasil Proses Belajar Mengajar. Bandung. Remaja Rosdakarya. 2013

Sanyoto, Ebdi Sadjiman. Dasar-Dasar Tata Rupa dan Desain Grafis (Nirmana). Yogyakarta. arti bumi intaran. 2005 